Pacific Journal of Mathematics

INDICES FOR THE ORLICZ SPACES 


\section{INDICES FOR THE ORLICZ SPACES}

\section{DAVID W. BOYD}

The determination of the function spaces $X$ which are intermediate in the weak sense between $L^{p}$ and $L^{q}$ has been shown, by the author, to depend on a pair of numbers $(\alpha, \beta)$ called the indices of the space. The indices depend on the function norm of $X$ and on the properties of the underlying measure space: whether it has finite or infinite measure, is non-atomic or atomic. In this paper, formulas are given for the indices of an Orlicz space in case the measure space is non-atomic with finite or infinite measure, or else is purely atomic with atoms of equal measure. The indices for an Orlicz space over a non-atomic finite measure space turn out to be the reciprocals of the exponents of the space as introduced by Matuszewska and Orlicz, and generalized by Shimogaki. Some new results concerning submultiplicative functions are used in the proof of the main result.

Definitions and MaIn Result. We suppose that $(\Omega, \mathscr{T}, \mu)$ is a measure space which is measure-theoretically isomorphic to one of the following three possibilities: the positive reals $\boldsymbol{R}^{+}$with Lebesgue measure, the interval $I=[0,1]$ with Lebesgue measure or the positive integers $\boldsymbol{Z}^{+}$with counting measure. We shall denote these standard spaces by $S_{i}$ with $i=0,1,2$ for $\boldsymbol{R}^{+}, I$ and $\boldsymbol{Z}^{+}$respectively. We shall write $\Omega^{*}=S_{i}$ if $(\Omega, \mathscr{T}, \mu)$ is isomorphic to $S_{i}$.

Suppose that $\rho$ is a rearrangement-invariant function norm on the measurable functions $\mathscr{C}(\Omega, \mathscr{T}, \mu)$ on $(\Omega, \mathscr{T}, \mu)$, (see [2]). Then for each measurable $f, \rho(f)=\sigma\left(f^{*}\right)$ where $f^{*}$ is the decreasing rearrangement of $f$ onto $\boldsymbol{R}^{+}$, and $\sigma$ is a rearrangement invariant norm on $\boldsymbol{R}^{+}$. We define $E_{s} f^{*}$ by $E_{s} f^{*}(t)=f^{*}(s t)$ for $0<s<\infty$, and then let

$$
h(s)=\sup \left\{\sigma\left(E_{s} f^{*}\right): f \in \mathscr{C l}(\Omega, \mathscr{T}, \mu), \sigma\left(f^{*}\right) \leqq 1\right\} .
$$

It is known that the following limits exist (see Lemma 1, below)

$$
\alpha=\lim _{s \rightarrow 0+} \frac{\log h(s)}{-\log s}, \beta=\lim _{s \rightarrow \infty} \frac{-\log h(s)}{\log s}
$$

and these are called the indices of the space $L^{\rho}(\Omega, \mathscr{T}, \mu)$. Note that in fact $\alpha$ depends only on $\sigma$ and on $\Omega^{*}$ so we will write $\alpha=\alpha\left(\sigma, \Omega^{*}\right)$ and $\beta=\beta\left(\sigma, \Omega^{*}\right)$. (A slightly different definition was used in case $\Omega^{*}=Z^{+}$when the indices were introduced in [2], but it is equivalent to the definition given here as Lemma 3 will show). It was shown in [2] that $X$ is intermediate between $L^{p}$ and $L^{q}$ in the weak sense if and only if $1 / p>\alpha$ and $\beta>1 / q$. 
We use the definition of Orlicz space given in [5]. Thus, let $\varphi$ be a right-continuous nondecreasing function on $[0, \infty]$ and let $\psi$ be its left-continuous inverse. Then the functions $\Phi$ and $\Psi$ defined by

$$
\Phi(u)=\int_{0}^{u} \varphi(t) d t, \Psi(u)=\int_{0}^{u} \Psi(t) d t
$$

are called complementary Young's functions. The general form of $\Phi$ (or $\Psi$ ) is that there are two numbers $a$ and $b$ with $0 \leqq a \leqq b \leqq \infty$ such that $\Phi(u)=0$ for $0 \leqq u \leqq a$, $\Phi$ is convex and finite valued in ]$a, b[$, and $\Phi(u)=\infty$ for $u>b$. If $b<\infty$ we say " $\Phi$ jumps" and if $a>0$ we say " $\Phi$ is level". Otherwise we say $\Phi$ is strictly increasing.

Define the Minkowski functional by

$$
M_{\Phi}\left(f^{*}\right)=\int_{0}^{\infty} \Phi\left(f^{*}(t)\right) d t,
$$

and then $\rho_{\Phi}(f)=\inf \left\{c: M_{\Phi}\left(c^{-1} f^{*}\right) \leqq 1\right\}=\sigma_{\Phi}\left(f^{*}\right)$. The space $L_{\mathscr{\phi}}(\Omega, \mathscr{T}, \mu)$ is the subspace of $\mathscr{C}(\Omega, \mathscr{T}, \mu)$ determined by the function norm $\rho_{\phi}$, and its dual space (in the sense of function spaces) is isomorphic to $L^{\psi}$.

We shall write $\alpha_{i}(\Phi)=\alpha\left(\sigma_{\varphi}, S_{i}\right) \quad(i=0,1,2)$. And similarly for $\beta$. Note that the indices of a space $X$ are invariant under isomorphism and that if $\left(\alpha^{\prime}, \beta^{\prime}\right)$ are the indices of the dual space of $L^{\rho}$, then $\left(\alpha^{\prime}, \beta^{\prime}\right)=(1-\beta, 1-\alpha)$ (see [2]). The case $i=0$ of the following theorem was proved in [1].

Theorem. Given a Young's function $\Phi$. For $0<s<\infty$, let

$$
\begin{aligned}
& g_{0}(s)=\sup \left\{\Phi^{-1}(t) / \Phi^{-1}(s t): 0<t<\infty\right\} \\
& g_{1}(s)=\lim \sup \left\{\Phi^{-1}(t) / \Phi^{-1}(s t): t \rightarrow \infty\right\} \\
& g_{2}(s)=\lim \sup \left\{\Phi^{-1}(t) / \Phi^{-1}(s t): t \rightarrow 0+\right\}
\end{aligned}
$$

Then

$$
\begin{array}{lr}
\alpha_{i}(\Phi)=\lim _{s \rightarrow 0+}-\log g_{i}(s) / \log s, & i=0,1,2 \\
\beta_{i}(\Phi)=\lim _{s \rightarrow \infty}-\log g_{i}(s) / \log s, & i=0,1,2 .
\end{array}
$$

\section{Preliminary lemmas.}

LEMMA 1. (a). Suppose that $h$ is a positive function which. satisfies $h(s t) \leqq h(s) h(t)$ for all $s>0$ and $t>0$. Let

$$
\theta(s)=-\log h(s) / \log s,
$$

and let

$$
\alpha(h)=\inf \{\theta(s): 0<s<1\}, \beta(h)=\sup \{\theta(s): s>1\} .
$$

Then 


$$
\alpha(h)=\lim _{s \rightarrow 0+} \theta(s) \quad \text { and } \quad \beta(h)=\lim _{s \rightarrow \infty} \theta(s) .
$$

(b). Suppose $h$ is positive and monotone and satisfies

$$
h(m n) \leqq h(m) h(n)
$$

for $m, n$ in $\boldsymbol{Z}^{+}$. Let $\theta(n)=-\log h(n) / \log n$, and

$$
\beta(h)=\inf \left\{\theta(n): n \in \boldsymbol{Z}^{+}\right\} \text {. }
$$

Then $\beta(h)=\lim _{n \rightarrow \infty} \theta(n)$.

Proof. The proof of (a) is in [1], and that of (b) is in [3]. Note that the extra condition in (b), that $h$ be monotone, is needed; otherwise, one could define $h(p)$ to be an arbitrary positive number for each prime $p$, and then if $n=p_{1}^{a_{1}} \cdots p_{k}^{a_{k}}$, let $h(n)=h\left(p_{1}\right)^{a_{1}} \cdots h\left(p_{k}\right)^{a_{k}}$. If $h(1)=1, h$ would satisfy (b) except that it would not be monotone, and certainly the conclusion need not be true, e.g., if $h(p)=p^{p}$.

Lemma 2. (a). Let $f$ be a positive function on $[1, \infty[$ and for $s>1$ let $h(s)=\sup _{t \geqq 1} f(s t) / f(t)$ and $h_{1}(s)=\lim _{\sup _{t \rightarrow \infty}} f(s t) / f(t)$. If $\beta$ is as in Lemma $1(a)$, then

$$
\beta(h)=\beta\left(h_{1}\right) .
$$

(b) Let $f$ be positive and monotone on $\boldsymbol{Z}^{+}$, and for $m \in \boldsymbol{Z}^{+}$, let

$$
h(m)=\sup _{n \in \mathbf{Z}^{+}} f(m n) / f(n),
$$

and $h_{1}(m)=\lim \sup _{n \rightarrow \infty} f(m n) / f(n)$. If $\beta$ is as in Lemma 1(b), then

$$
\beta(h)=\beta_{1}(h) \text {. }
$$

Proof. (a) Clearly $h$ satisfies the condition of Lemma 1 (a) for $s \geqq 1, t \geqq 1$. Let $\beta=\beta(h)$. By definition of $\beta$ and the conclusion of Lemma 1 , there is a function $\varepsilon(s)$ such that $\varepsilon(s) \geqq 0$ and $\varepsilon(s) \rightarrow 0$ as $s \rightarrow \infty$ such that

$$
s^{-\beta} \leqq h(s) \leqq s^{-\beta+\varepsilon(s)} \text { for } s \geqq 1 .
$$

Define $\Delta(t, s)=f(s t) / f(t)$. Let $m$ be a positive integer, and $s$ be fixed $>1$. Then there is a $t_{m}$ so that

Using (1),

$$
h\left(s^{m}\right) \leqq \Delta\left(t_{m}, s^{m}\right) s \text {. }
$$

$$
\Delta\left(t_{m}, s^{m}\right) \geqq s^{-\beta m-1} \text {. }
$$

Note that, for any $t$, 


$$
\Delta\left(t s^{n}, s\right)=f\left(s^{n+1} t\right) / f\left(s^{n} t\right)
$$

so that

$$
\begin{aligned}
\prod_{n=m}^{2 m-1} \Delta\left(t_{2 m} s^{n}, s\right) & =\Delta\left(t_{2 m}, s^{2 m}\right) / \Delta\left(t_{2 m}, s^{m}\right) \\
& \geqq s^{-2 \beta m-1} / s^{-\beta m+\varepsilon} \\
& =s^{-\beta m-1-\varepsilon}
\end{aligned}
$$

where $\varepsilon=\varepsilon\left(s^{m}\right)$.

Thus, if $n_{m}$ is such that

$$
\Delta\left(t_{2 m} s^{n}, s\right)=\max \left\{\Delta\left(t_{2 m} s^{n}, s\right): m \leqq n \leqq 2 m-1\right\},
$$

one has

$$
\Delta\left(t_{2 m} s^{n}, s\right)^{m} \geqq \prod_{n=m}^{2 m-1} \Delta\left(t_{2 m} s^{n}, s\right)
$$

and thus

$$
\Delta\left(t_{2 m} s^{n_{m}}, s\right) \geqq s^{-\beta-(1 / m)-(\varepsilon / m)} .
$$

But

$$
t_{2 m} s^{n} \geqq s^{m} \rightarrow \infty \quad \text { as } \quad m \rightarrow \infty
$$

Hence

$$
h_{1}(s) \geqq \lim _{m \rightarrow \infty} \sup \Delta\left(t_{2 m} s^{n}, s\right) \geqq s^{-\beta}
$$

for any $s>1$, which shows that $\beta\left(h_{1}\right)=\beta(h)$, since obviously $h_{1}(s) \leqq$ $h(s)$. (b) The proof is entirely the same, using Lemma 1 (b) rather than 1 (a).

LEMMA 3. Suppose that $f$ is positive and monotone on $[1, \infty$ [ that

$$
h_{1}(s)=\limsup _{t \rightarrow \infty} \frac{f(s t)}{f(t)} \quad \text { and } \quad h_{2}(s)=\limsup _{n \rightarrow \infty} \frac{f(s n)}{f(n)} \quad \text { for } \quad s>0 .
$$

Then

$$
h_{2}(s) \leqq h_{1}(s) \leqq h_{2}(s \pm)
$$

where the upper (lower) sign is used if $f$ is increasing (decreasing), and

$$
\beta\left(h_{2}\right)=\beta\left(h_{1}\right)
$$

Proof. Clearly $h_{2}(s) \leqq h_{1}(s)$. We treat the case that $f$ is decreasing.

Given $\varepsilon>0, s>1$ and an integer $m \geqq 1$, there is an $N \geqq m$ such that $n \geqq m$ implies 


$$
\frac{f\left(\left(s-s m^{-1}\right) n\right)}{f(n)} \leqq h_{2}\left(s-s m^{-1}\right)+\varepsilon .
$$

Since $f$ is decreasing, and $\left(s-s m^{-1}\right) n \leqq\left(s-s n^{-1}\right) n=s(n-1)$, we have

$$
\frac{f(s(n-1))}{f(n)} \leqq h_{2}\left(s-s m^{-1}\right)+\varepsilon, \quad \text { for } n \geqq N .
$$

Now if $t \geqq N+1$, then there is an integer $n \geqq N$ such that

$$
n-1 \leqq t<n
$$

so that $f(n-1) \geqq f(t) \geqq f(n)$, and $f(s(n-1)) \geqq f(s t) \geqq f(s n)$. Hence

$$
\frac{f(s t)}{f(t)} \leqq \frac{f(s(n-1))}{f(n)} \leqq h_{2}\left(s-s m^{-1}\right)+\varepsilon \quad \text { for } t \geqq N+1 \text {. }
$$

Thus

$$
h_{1}(s) \leqq h_{2}\left(s-s m^{-1}\right)+\varepsilon \quad \text { for all } m \text { and } \varepsilon
$$

so that

$$
h_{1}(s) \leqq h_{2}(s-) \text {. }
$$

Clearly $\beta\left(h_{2}\right)=\beta\left(h_{1}\right)$ follows from these inequalities.

Proof of the Theorem. $i=0$. This was proved in [1], Theorem 5.5. In fact, in this case, $h(s)=g_{0}(s)$ for all $s$.

$i=1$. We prove first that $\beta_{1}(\Phi)$ is as in the statement of the theorem. Then we use $\alpha_{1}(\Phi)=1-\beta_{1}(\Psi)$, and the well-known inequality:

$$
t / \Phi^{-1}(t) \leqq \Psi^{-1}(t) \leqq 2 t / \Phi^{-1}(t) \quad \text { for all } t>0
$$

to show that the expression for $\alpha_{1}(\Phi)$ is as stated. (For the inequality see [4], p. 13).

Let us thus take $s>1$. We recall that if $E$ is a set of measure $u$ and $\chi_{E}$ is its characteristic function, then $\chi_{E}^{*}=\chi[0, u]=\chi_{u}$, and $\sigma_{\Phi}\left(\chi_{u}\right)=1 / \Phi^{-1}(1 / u)$, so that

$$
\begin{aligned}
h(s) & =\sup \left\{\sigma_{\Phi}\left(E_{s} f^{*}\right) / \sigma_{\Phi}\left(f^{*}\right): f \neq 0, f \in L^{\Phi}(I)\right\} \\
& \geqq \sup \left\{\sigma_{\Phi}\left(E_{s} \chi_{u}\right) / \sigma_{\Phi}\left(\chi_{u}\right): 0<u \leqq 1\right\} \\
& =\sup \left\{\Phi^{-1}\left(u^{-1}\right) / \Phi^{-1}\left(s u^{-1}\right): 0<u \leqq 1\right\} \\
& =\sup \left\{\Phi^{-1}(t) / \Phi^{-1}(s t): t \geqq 1\right\} .
\end{aligned}
$$

We define the latter quantity to be $k(s)$. Then (4) implies

$$
\beta(h) \leqq \beta(k) \text {. }
$$


Note that by Lemma 2,

$$
\beta(k)=\beta\left(g_{1}\right) .
$$

Now we proceed to show that $h(s) \leqq k(s / 2)$ for $s \geqq 2$, which clearly implies $\beta(h) \geqq \beta(k)$ so that

$$
\beta(h)=\beta(k)=\beta\left(g_{1}\right) .
$$

Assume now that $\Phi$ is strictly increasing. We leave the other cases to the reader.

By definition of $k(s)$,

$$
\Phi^{-1}(t) / k(s) \leqq \Phi^{-1}(s t) \quad \text { for } s \geqq 1, t \geqq 1 .
$$

Thus,

$$
\Phi\left(\Phi^{-1}(t) / k(s)\right) \leqq s t, \quad s \geqq 1, t \geqq 1
$$

and so

$$
\Phi(u / k(s)) \leqq s \Phi(u), \quad \text { for } u \geqq \Phi^{-1}(1) \text {. }
$$

Given $0<f \in L^{\Phi}(I)$ with $f$ decreasing let

$$
c=\sup \left\{t: f(t) \geqq \Phi^{-1}(1)\right\} \text {. }
$$

Then from (5),

and

$$
\Phi(f(t) / k(s)) \leqq s \Phi(f(t)), \quad 0 \leqq t \leqq c
$$

$$
\Phi(f(t) / k(s)) \leqq \Phi\left(\Phi^{-1}(1) / k(s)\right) \leqq s, \quad \text { for } c<t \leqq 1 .
$$

Hence, for $s \geqq 2$, (6) implies that

$$
\begin{aligned}
M_{\Phi}\left(E_{s} f / k(s / 2)\right) & =\int_{0}^{1 / s} \Phi(f(s t) / k(s / 2)) d t \\
& =s^{-1} \int_{0}^{1} \Phi(f(t) / k(s / 2)) d t \\
& =s^{-1}\left(\int_{0}^{c} \frac{s}{2} \Phi(f(t)) d t+\int_{c}^{1} \frac{s}{2} d t\right) \\
& \leqq \frac{1}{2} \int_{0}^{1} \Phi(f(t)) d t+\frac{1}{2} \leqq 1, \quad \text { if } M_{\Phi}(f) \leqq 1 .
\end{aligned}
$$

Thus,

$$
\rho\left(E_{s} f\right) \leqq k(s / 2) \quad \text { for } \rho(f) \leqq 1,
$$

which proves that

$$
h(s) \leqq k(s / 2) \quad \text { for } s \geqq 2 \text {. }
$$


$i=2$. According to Lemma 4 of [2], if $F_{m}$ is the operator on sequences $\{f(n)\}$ given by

$$
F_{m} f(n)=f([(n-1) / m]+1),
$$

and if

$$
K(m)=\sup \left\{\rho\left(F_{m} f\right): f \in L^{\circ}\left(Z^{+}\right), \rho(f) \leqq 1\right\}
$$

then

$$
\alpha_{2}=\lim _{n \rightarrow \infty} \log K(m) / \log m=-\beta(K) \text {. }
$$

Note that the action of $F_{m}$ on $\{f(1), f(2), \cdots\}$ is to repeat each term $m$-times, e.g., $F_{2}\{f(1), f(2), \cdots\}=\{f(1), f(1), f(2), f(2), \cdots\}$. Let us define

$$
p(m)=\sup _{0<u \leqq 1} \Phi^{-1}(u) / \Phi^{-1}(u / m) \quad \text { for } m \in Z^{+} .
$$

Then, as in (5) above we obtain

$$
\Phi(t / p(m)) \leqq m^{-1} \Phi(t) \quad \text { provided } \mathrm{t} \leqq \Phi^{-1}(1) .
$$

Observe that, if $0 \leqq f \in L^{\Phi}$, and $k$ is fixed, then $f(k) \chi_{\{k\}}(n) \leqq f(n)$ for all $n=1,2, \cdots$ so that

That is

$$
\rho_{\Phi}\left(f(k) \chi_{\{k\}}\right) \leqq \rho_{\Phi}(f) .
$$

$$
f(k) \leqq \rho_{\Phi}(f) / \rho_{\Phi}\left(\chi_{(k)}\right)=\rho_{\Phi}(f) \Phi^{-1}(1), \quad \text { for all } k .
$$

Hence, if $\rho_{\Phi}(f) \leqq 1$, we have from (7) that

$$
\Phi(f(k) / p(m)) \leqq m^{-1} \Phi(f(k)) \quad \text { for all } k \text { and } m \text {. }
$$

Thus

$$
\begin{aligned}
M_{\Phi}\left(F_{m} f / p(m)\right) & =\sum_{n=1}^{\infty} \Phi\left(F_{m} f(n) / p(m)\right) \\
& =m \sum_{n=1}^{\infty} \Phi(f(n) / p(m)), \quad \text { by an earlier remark, } \\
& \leqq m \sum_{n=1}^{\infty} m^{-1} \Phi(f(n))=M_{\Phi}(f) .
\end{aligned}
$$

Thus,

$$
K(m) \leqq p(m)
$$

But, if $f=\chi_{\{1,2, \ldots, k\}}$, then

$$
\rho\left(F_{m} f\right) / \rho_{\Phi}(f)=\Phi^{-1}\left(k^{-1}\right) / \Phi^{-1}\left(k^{-1} m^{-1}\right) .
$$

Thus

$$
K(m) \geqq \sup _{k \in Z^{+}} \Phi^{-1}\left(k^{-1}\right) / \Phi^{-1}\left(k^{-1} m^{-1}\right)=p_{1}(m), \quad \text { say . }
$$

By Lemma 2, with $f(t)=1 / \Phi^{-1}(1 / t)$, if 


$$
\hat{p}(m)=\lim _{t \rightarrow \infty} \sup \Phi^{-1}(1 / t) / \Phi^{-1}(1 / t m)
$$

and

$$
\hat{p}_{1}(m)=\limsup _{n \rightarrow \infty} \Phi^{-1}(1 / n) / \Phi^{-1}(1 / n m),
$$

then $\beta(p)=\beta(\hat{p})$ and $\beta\left(p_{1}\right)=\beta\left(\hat{p}_{1}\right)$. And, by Lemma 3, $\beta(\hat{p})=\beta\left(\hat{p}_{1}\right)$. Hence $\beta(K)=\beta(p)=\beta\left(p_{1}\right)$ and we thus obtain

$$
\begin{aligned}
\alpha_{2}(\Phi) & =\lim _{m \rightarrow \infty}-\log g_{2}\left(m^{-1}\right) / \log \left(m^{-1}\right) \\
& =\lim _{s \rightarrow 0+}-\log g_{2}(s) / \log s .
\end{aligned}
$$

As in the case $i=1$, we can obtain the result for $\beta_{2}(\Phi)$ from this and the inequality (3).

REMARK. One can relate the functions $g_{i}(s)$ to the functions $K_{i}(s)$ which are given by

$$
\begin{aligned}
& K_{0}(s)=\sup \{\Phi(s t) / \Phi(t): 0<t<\infty\} \\
& K_{1}(s)=\lim \sup \{\Phi(s t) / \Phi(t): t \rightarrow \infty\} \\
& K_{2}(s)=\lim \sup \{\Phi(s t) / \Phi(t): t \rightarrow 0+\}
\end{aligned}
$$

whenever these make sense (e.g., if $\Phi$ is strictly increasing).

In fact $K_{i}$ is left-continuous and increasing and its right continuous inverse is $1 / g_{i}$. Formally this is clear, since if we let

$$
\theta_{t}(s)=\Phi(s t) / \Phi(t)
$$

for any $t>0$, then $\theta_{t}$ is convex and increasing and

$$
\theta_{t}^{-1}(u)=\Phi^{-1}(u \Phi(t)) / t
$$

so that

$$
\theta_{\Phi^{-1}(t)}^{-1}(s)=\Phi^{-1}(s t) / \Phi^{-1}(t) .
$$

Thus we would expect

$$
\inf _{t>0} \theta_{\Phi^{-1}(t)}^{-1}(s)=1 / g_{0}(s)=\left(\sup _{t>0} \theta_{t}\right)^{-1}(s)=K_{0}^{-1}(s),
$$

and similarly for lim inf as $t \rightarrow 0+$ or $t \rightarrow \infty$. This intuitive argument can be justified as is done in [1] for the special case $i=0$. This shows that if $\sigma_{\Phi}, s_{\Phi}$ are the exponents defined in [6] and [7] for the case that $\Omega=[0,1]$, then $\alpha_{1}=1 / s_{\Phi}, \beta_{1}=1 / \sigma_{\Phi}$.

EXAMPLE. Let

$$
\begin{array}{cr}
\Phi(t)=e^{t}-t-1, & t \geqq 0 \\
\Psi(t)=(1+t) \log (1+t), & t \geqq 0 .
\end{array}
$$


Then, for $K_{0}$ as above

$$
K_{0}(s)=\left\{\begin{array}{l}
s^{2}, 0 \leqq s \leqq 1 \\
\infty, s>1
\end{array}\right.
$$

For, $\Phi(s t)-s^{2} \Phi(t)=\sum_{n=2}^{\infty}\left(\left(s^{n}-s^{2}\right) / n !\right) t^{n} \leqq 0$, for $0 \leqq s \leqq 1$, showing that $K_{0}(s) \leqq s^{2}$ for $0 \leqq s \leqq 1$ and $\Phi(s t) / \Phi(t) \rightarrow s^{2}$ as $t \rightarrow 0$. Also

$$
\lim _{t \rightarrow \infty} \Phi(s t) /(t)=\infty \text { for } s>1 \text {, showing } K_{0}(s)=\infty, \quad s>1 .
$$

Thus,

$$
g_{0}(s)=\max \left(s^{-1 / 2}, 1\right) .
$$

For large $t, \Phi(t) \sim e^{t}$ so $\Phi^{-1}(t) \sim \log t$, and hence

$$
g_{1}(s)=1 \text {. }
$$

For small $t, \Phi(t) \sim \frac{1}{2} t^{2}$ so $\Phi^{-1}(t) \sim \sqrt{ } 2 t$, and thus

$$
g_{2}(s)=s^{-1 / 2} \text {. }
$$

Hence

$$
\left(\alpha_{0}, \beta_{0}\right)=\left(\frac{1}{2}, 0\right),\left(\alpha_{1}, \beta_{1}\right)=(0,0),\left(\alpha_{2}, \beta_{2}\right)=\left(\frac{1}{2}, \frac{1}{2}\right)
$$

REMARK. The result given in Lemma 2 seems to be new. There is a corresponding result for subadditive function on $[0, \infty$, which may be obtained by setting $x=\log t, y=\log s$ and

$$
F(x)=\exp (f(\log x))
$$

in that lemma.

\section{REFERENCES}

1. D. W. Boyd, The Hilbert transform on rearrangement invariant spaces, Canad. J. Math., 19 (1967), 599-616.

2. Indices of function spaces and their relationship to interpolation, Canad. J. Math., 21 (1969), 1245-1254.

3. - Monotone semigroups of operators on cones, Canad. Math. Bull., 12 (1969), 299-310.

4. M. A. Krasnosel'skii, and Ya. B. Rutickii, Convex functions and Orlicz spaces, (Groningen, 1961).

5. W. A. J. Luxemburg, Banach Function Spaces, Thesis, Delft Technical Univ. (1955).

6. W. Matuszewska and W. Orlicz, On certain properties of $\varphi$-functions, Bull. Acad. Polon. Sci, Ser. sci. math. astr. et phys., 8 (1960), 439-443.

7. T. Shimogaki, Exponents of norms in semi-ordered linear spaces, Bull. Acad. Polon. Sci, Ser. math. astr. et phys., 13 (1965), 135-140.

Received June 17, 1970. Supported in part by NSF Grant GP-14133. 



\section{PACIFIC JOURNAL OF MATHEMATICS}

\section{EDITORS}

\author{
H. SAMELSON \\ Stanford University \\ Stanford, California 94305 \\ C. R. HовBY \\ University of Washington \\ Seattle, Washington 98105
}

J. DUGUndis

Department of Mathematics

University of Southern California

Los Angeles, California 90007

RICHARD ARENS

University of California

Los Angeles, California 90024

\section{ASSOCIATE EDITORS}
E. F. BeCKenbaCH
B. H. NeUmanN
F. WOLF
K. YoshidA

\section{SUPPORTING INSTITUTIONS}

\author{
UNIVERSITY OF BRITISH COLUMBIA \\ CALIFORNIA INSTITUTE OF TECHNOLOGY \\ UNIVERSITY OF CALIFORNIA \\ MONTANA STATE UNIVERSITY \\ UNIVERSITY OF NEVADA \\ NEW MEXICO STATE UNIVERSITY \\ OREGON STATE UNIVERSITY \\ UNIVERSITY OF OREGON \\ OSAKA UNIVERSITY \\ UNIVERSITY OF SOUTHERN CALIFORNIA
}

\author{
STANFORD UNIVERSITY \\ UNIVERSITY OF TOKYO \\ UNIVERSITY OF UTAH \\ WASHINGTON STATE UNIVERSITY \\ UNIVERSITY OF WASHINGTON

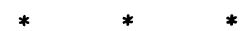 \\ AMERICAN MATHEMATICAL SOCIETY \\ CHEVRON RESEARCH CORPORATION \\ NAVAL WEAPONS CENTER
}

The Supporting Institutions listed above contribute to the cost of publication of this Journal, but they are not owners or publishers and have no responsibility for its content or policies.

Mathematical papers intended for publication in the Pacific Journal of Mathematics should be in typed form or offset-reproduced, (not dittoed), double spaced with large margins. Underline Greek letters in red, German in green, and script in blue. The first paragraph or two must be capable of being used separately as a synopsis of the entire paper. The editorial "we" must not be used in the synopsis, and items of the bibliography should not be cited there unless absolutely necessary, in which case they must be identified by author and Journal, rather than by item number. Manuscripts, in duplicate if possible, may be sent to any one of the four editors. Please classify according to the scheme of Math. Rev. Index to Vol. 39. All other communications to the editors should be addressed to the managing editor, Richard Arens, University of California, Los Angeles, California, 90024.

50 reprints are provided free for each article; additional copies may be obtained at cost in multiples of 50 .

The Pacific Journal of Mathematics is published monthly. Effective with Volume 16 the price per volume (3 numbers) is $\$ 8.00$; single issues, $\$ 3.00$. Special price for current issues to individual faculty members of supporting institutions and to individual members of the American Mathematical Society: $\$ 4.00$ per volume; single issues $\$ 1.50$. Back numbers are available.

Subscriptions, orders for back numbers, and changes of address should be sent to Pacific Journal of Mathematics, 103 Highland Boulevard, Berkeley, California, 94708.

PUBLISHED BY PACIFIC JOURNAL OF MATHEMATICS, A NON-PROFIT CORPORATION

Printed at Kokusai Bunken Insatsusha (International Academic Printing Co., Ltd.), 7-17, Fujimi 2-chome, Chiyoda-ku, Tokyo, Japan. 


\section{Pacific Journal of Mathematics}

Vol. 38, No. $2 \quad$ April, 1971

Richard Davis Anderson and Thomas Ashland Chapman, Extending

homeomorphisms to Hilbert cube manifolds .................. 281

Nguyen Huu Anh, Restriction of the principal series of $\operatorname{SL}(n, \mathbf{C})$ to some

reductive subgroups................................ 295

David W. Boyd, Indices for the Orlicz spaces . . . . . . . . . . . . 315

William Garfield Bridges, The polynomial of a non-regular digraph ...... 325

Billie Chandler Carlson, Robert K. Meany and Stuart Alan Nelson, Mixed

arithmetic and geometric means........................ 343

H. A. Çelik, Commutative associative rings and anti-flexible rings ...... 351

Hsin Chu, On the structure of almost periodic transformation groups ...... 359

David Allyn Drake, The translation groups of n-uniform translation

Hjelmslev planes ................................ 365

Michael Benton Freeman, The polynomial hull of a thin two-manifold . . . . 377

Anthony Alfred Gioia and Donald Goldsmith, Convolutions of arithmetic

functions over cohesive basic sequences .................... 391

Leslie C. Glaser, A proof of the most general polyhedral Schoenflies

conjecture possible ................................

Thomas Lee Hayden and Ted Joe Suffridge, Biholomorphic maps in Hilbert

space have a fixed point ................................ 419

Roger Alan Horn, Schlicht mappings and infinitely divisible kernels ...... 423

Norman Ray Howes, On completeness ...................... 431

Hideo Imai, Sario potentials on Riemannian spaces................ 441

A. A. Iskander, Subalgebra systems of powers of partial universal

algebras.

Barry E. Johnson, Norms of derivations of $\mathscr{L}(\mathrm{X})$.

David Clifford Kay and Eugene W. Womble, Axiomatic convexity theory and relationships between the Carathéodory, Helly, and Radon numbers

Constantine G. Lascarides, A study of certain sequence spaces of Maddox

and a generalization of a theorem of Iyer .............

C. N. Linden, On Blaschke products of restricted growth .

John S. Lowndes, Some triple integral equations ................. 515

Declan McCartan, Bicontinuous preordered topological spaces ......... 523

S. Moedomo and J. Jerry Uhl, Jr., Radon-Nikodým theorems for the Bochner and Pettis integrals ...

Calvin Cooper Moore and Joseph Albert Wolf, Totally real representations

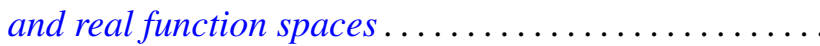

Reese Trego Prosser, A form of the moment problem for Lie groups. ... 